\title{
Defining an Architectural Design Strategy for Energy Performance - A Systematic Approach for Students
}

\author{
A. H. Mokhtar ${ }^{1}$ \\ ${ }^{1}$ College of Architecture, Art, and Design, American University of Sharjah, P.O. Box \\ 26666, Sharjah, United Arab Emirates; PH (+971) 6515 2834; FAX (+971) 6515 \\ 2800; email: mokhtar@aus.edu
}

\begin{abstract}
Managing the energy performance of a building should start from the pre-conceptual design phase. Architects at this phase need to analyze the nature of the site environment, the nature of the building, and the comfort requirements of the occupants. An accurate analysis of these elements helps them formulate a design strategy for optimizing energy performance. However, this requires good understanding of the energy behavior of buildings. Such understanding optimally starts at the undergraduate architecture education. This paper presents a systematic approach to construct such understanding through a required course in an architectural curriculum. The paper explains the subjects covered in the course for a student to grasp the fundamentals of analyzing a project from an energy performance point of view. It also explains how to help students manipulate environmental forces and create a building's form that supports optimizing its energy performance. Finally, it discusses the common difficulties to propagate this systematic approach through the rest of the curriculum.
\end{abstract}

\section{INTRODUCTION}

Architectural design decisions have an important impact on the energy performance of a building. During conceptual design, the forms of the building's masses, their orientation, their solar and wind shadow on one another, and their location on the site are among the critical energy-related early design decisions. Throughout design development, decisions on components such as shading devices, envelope materials, and finishing surfaces also impact greatly the building's energy performance. Yet, many architects do not adequately consider the energy impact of these architectural design decisions. Their approach is to leave it to engineers to find solutions that accommodate such impact. While engineering solutions can improve the energy performance, many of these solutions mainly solve problems that could have been avoided by a better architectural design at an earlier stage. This approach typically results in increasing cost and prevents the attaining of a high quality design from the energy performance point of view. At a time when there is an increasing demand to control global warming, some see an additional ethical problem in such an approach. Others see loss of opportunities to enrich the built environment with new forms that are generated from the need to improve buildings energy performance. 
Yet putting an emphasis on energy performance during the early design stages requires an adequate understanding of the energy behavior of buildings and how architectural design decisions impact such behavior. Constructing such understanding should begin in undergraduate architectural curricula. These should not only identify to students the principles of physics that control the behavior of environmental energies affecting the built environment (e.g. sun and wind), but should also provide an opportunity for students to define design strategies that manipulate these environmental energies.

Unfortunately, this is not common in architectural curricula. Effort is being done by some architecture faculty to change this and to embed energy issues in architectural education. This paper intends to contribute to such effort. The paper begins with a review of some related work and then discusses the rationale and structure of a course that provides a systematic approach for defining an architectural design strategy for energy performance. Finally, a summary and conclusion provides the author's view on the challenges facing a better inclusion of such design approach in the curriculum, particularly in studios.

The course covered in this paper belongs to the technical track of courses that are part of the Bachelor of Architecture curriculum at the American University of Sharjah (AUS). AUS was established in 1997 in the Emirate of Sharjah (a neighbor emirate of Dubai) and is accredited by the Middle States Commission on Higher Education in the United States of America. The Bachelor of Architecture program is accredited by The National Architectural Accrediting Board (NAAB).

\section{RELATED WORK}

Several textbooks address the fundamentals of environmental energies as they relate to the built environment. Some are oriented towards architecture students where the fundamentals are simplified and a large number of illustrations are provided (Szokolay, 2008, McMullan, 2007, and Pohl, 2011). Others have a greater amount of detail on the physics and the relevant equations (Hutcheon and Handegord, 1995). The later texts are oriented more towards specialized students such as architectural engineering and graduate students. Reference books on the subject also exist, for example the ASHRAE handbook, which provides important design data worldwide (ASHRAE, 2009). There is also a variety of software relating to the fundamentals of environmental energies. These typically aim to analyze the energy consumption of buildings. Most provide detailed calculations that are necessary to simulate an energy performance for the purpose of air conditioning design such as eQuest (U.S. Department of Energy, 2010) and EnergyPlus (U.S. Department of Energy, 2011a). Some are oriented towards architectural conceptual design such as Ecotect (Autodesk, 2012). More integration of easier modeling tools and better energy simulation tools are appearing such as linking Sketch up and EnergyPlus (U.S. Department of Energy, 2011b). A comprehensive list of related tools is collected for the Carbon Neutral Design Project (SBSE and AIA, 2012). The website of this project has contributions from many architecture faculty and includes their pedagogical philosophies and strategies. 
Important work has been done to document the teaching of ecological design (which typically includes environmental energies) in architectural programs in the USA and Canada (AIA, 2006 and Earley, 2005). However, no published paper was found that addresses approaches to teaching fundamentals of environmental energies in architecture curricula. Clearly more needs to be done to document and distribute the effort made by the many architecture faculty who are tackling this subject, and to open up the discussion with the wider architecture faculty.

\section{THE APPROACH}

The subject of energy performance of buildings is a complex and multi-faceted one. Defining an appropriate design strategy that saves energy for a particular project is a challenging task for a student. The author found it common among students to decide on a strategy (e.g. natural ventilation or passive heat gain) based on ad hoc criteria that seem to depend on gut feeling. In many students' projects seen by the author, collected - and not analyzed - climate data contradicts with the selected energy saving design strategy. Furthermore, the selected design strategy is not carried all the way through the following design stages (e.g. using a natural ventilation strategy but hardly providing operable openings in the building). The author sees that making such ad hoc decisions is a result of the pressure to address the energy performance aspect of buildings but without a clear approach on how to do so.

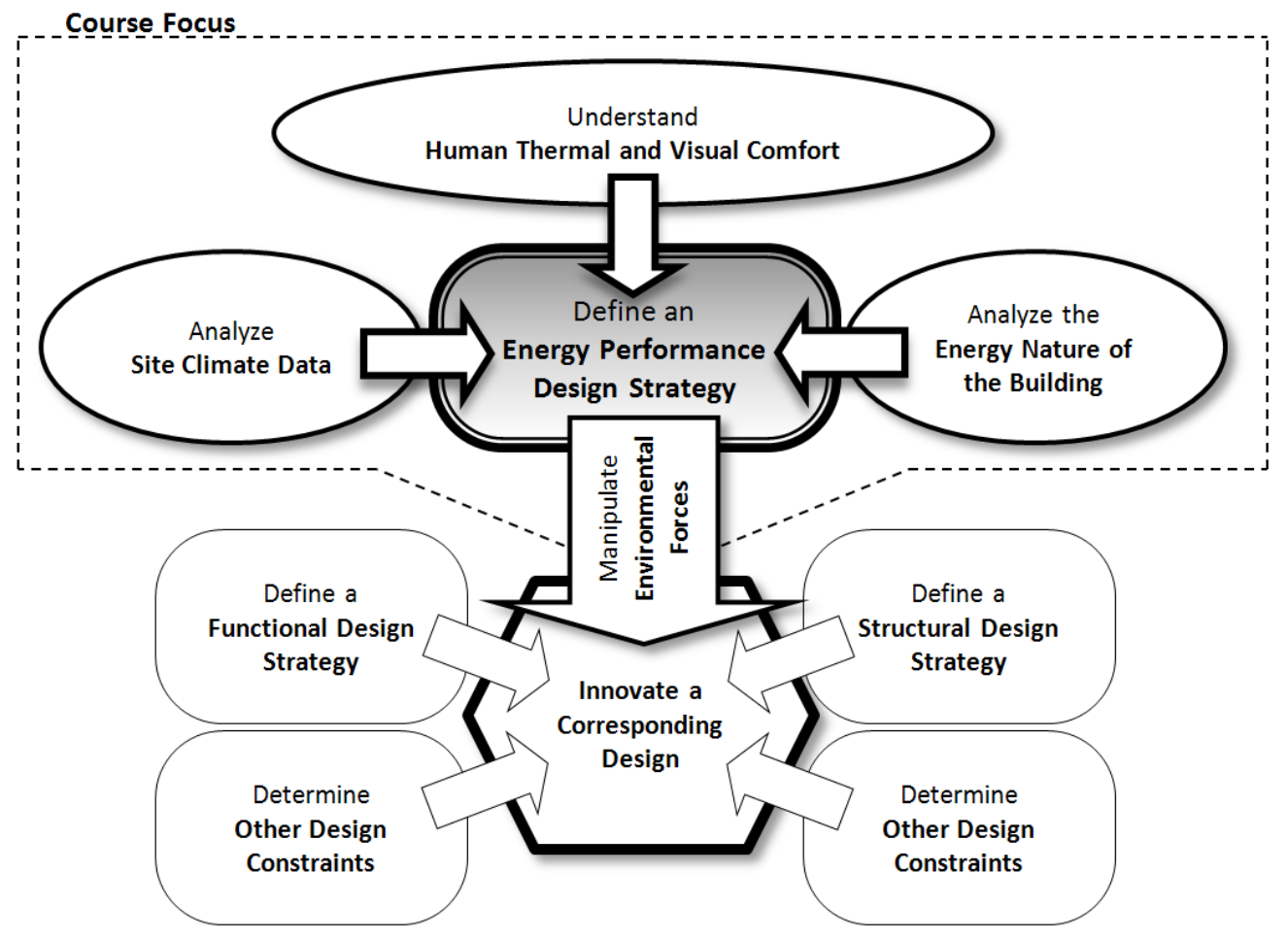

Figure 1. Components of the systematic approach 
In the described course, the author aims to help students formulate an appropriate energy performance design strategy through using a systemic approach. As shown in the Figure 1, the approach is based on addressing three fundamental aspects:

1. Understanding human thermal and visual comfort, as most energy used in a building is to satisfy these two human needs.

2. Analyzing site climate data, as it provides information on the environmental forces that need to be manipulated by the building's design to provide the human thermal and visual comfort.

3. Analyzing the energy nature of the building itself and how aspects like its function and schedule of use can inform a design strategy.

The energy performance design strategy should be formulated to reflect the result of the understanding and the analysis of the above three aspects. The course discusses several examples of these design strategies through case studies. In discussing these strategies, the instructor highlights the impact of the selected strategy on the building form and how an energy performance strategy can derive the architectural vocabulary.

Once an energy performance design strategy is formulated (e.g. natural ventilation), students need to understand more about the physical nature of the relevant environmental forces (e.g. wind). Such understanding helps them to appropriately manipulate these forces to achieve their design intentions. The course focuses on three main forces which are the Sun, wind, and the thermal energy of air.

\section{COURSE STRUCTURE}

To reflect the proposed systematic approach, the course is structured into two distinct categories of subjects: foundational knowledge and the manipulation of environmental forces. This section briefly explains how the subjects of each category are addressed in the course.

\section{Foundational Knowledge}

This category of subjects focuses on understanding the bases on which a student can identify an appropriate energy performance design strategy. As discussed above, these bases cover the following subjects:

\section{Understanding the fundamentals of human thermal and visual comfort}

Achieving human thermal and visual comfort is the ultimate objective for consuming significant portion of energy in buildings. To understand the requirements of this objective, students are taken through a journey of discovering how their bodies work as thermal objects, including the internal generation of energy and the release of a portion of this energy into the surroundings by different means. Human body reactions to extreme conditions are discussed and hence the idea of adapting comfortably to the thermal environment is recognized. The six factors that affect the generation and release of energy by the human body are deduced systematically and 
examples are given of how humans manipulate these factors in their daily lives. Equipment that measures air temperature, air speed, mean radiant temperature, and relative humidity are used to measure these conditions both inside and outside the classroom. These measurements give students a sense of meaning of the surrounding environment data (for example, how it feels to have $3 \mathrm{~m} / \mathrm{s}$ wind speed). The Bioclimatic Chart (Olgyay, 1992) is used to facilitate the understanding of the interrelationship between the six factors that affect human thermal comfort. Architecture design strategies that aim to manipulate one or more of these factors are introduced and discussed.

The subject also covers the nature of light and the terminology used for measuring light levels. A simple lux meter is used to help students develop an appreciation of the light level in class and outdoors. The subject also covers the structure of the eye and its adaptation to different light levels. Finally, the expected light levels for different functions are discussed.

\section{Analyzing the site climate}

This part of the course aims to help students correctly interpret climate data of a site and select an appropriate design strategy. Components of typical climatic data are identified and their importance to architectural design decisions is discussed. Wind speed and direction, air temperature, sky cover, and relative humidity are analyzed through reading the data. Graphic representations of the data are shown using Climate Consultant software (Ligget and Mine, 2011). The graphic representation, along with contrasting data from different climatic zones, significantly facilitates the interpretation of the data (Figure 2). Relevant design strategies are identified to match the climatic conditions of each region.
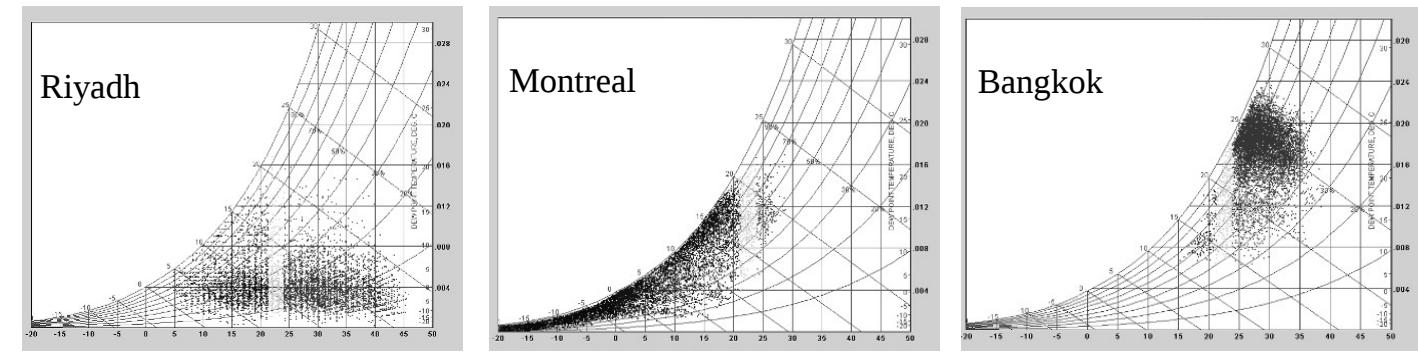

Figure 2. Comparison of psychrometric chart data for cities in different climates (Colligation from Climate Consultant outputs)

Analyzing the energy nature of the building

This part of the course aims to help students recognize that not only the site climate but also the nature of the designed building influences the design strategy. This nature includes the type of activities performed in the building and the schedule of performing these activities. It also includes the proportions of the building's mass (e.g. an office tower vs. a one-story shopping mall). To understand the subject, group activities are formed, and with the help of the instructor, students identify the elements that contribute to internal and external heat gain (or loss) in a building. Emphasis is put on recognizing the most critical of these elements for different types 
of building functions and building's mass proportions. For example, students recognize that internal heat gain is more critical in a shopping mall than in a villa. Or that the heat gain from the roof is not as critical in a high-rise building as it is in a one-floor warehouse.

Once the critical sources of heat gain are recognized, the relevant bioclimatic design strategies that address these sources are explored. An exercise is given for three building types that are located in different climatic conditions. In each case, students need to identify the critical sources for heat gain or loss. Based on that identification, they select appropriate bioclimatic design strategies that mitigate any excessive gain or loss from these critical sources. Simple energy load software is used to assist students throughout the learning process. The software allows them to easily manipulate elements of building design and see the implications of such manipulation on heat gain and loss for different building types in different climates.

\section{ENVIRONMENTAL FORCES TO MANIPULATE}

This category of subjects focuses on understanding the nature and explores the design manipulation of two essential environmental forces for energy performance; Sun and air. The air is viewed from two points of view, the first being its movement in the form of wind and the second its thermal energy contents.

\section{Nature and design manipulation of solar energy}

The main objective here is to help students make design decisions that manage heat gain from the Sun. This requires a good understanding of the following:

The relationship between the Sun and Earth, and hence how to correctly locate the Sun in the sky at any time and for any location. The Solar Tool of the software Autodesk Ecotect (Autodesk, 2012) is used to demonstrate this information graphically through comparing the Sun's path at different altitudes.

$\square$ The factors that affect the quantity of solar energy received by a building surface, and how design decisions can manipulate some of these factors to manage this quantity. Two of these critical design decisions for a building surface are its form and orientation. A software called SIBS (Mokhtar, 2006) is used in an assignment that challenges students in making forms that minimize (or maximize) the exposure of a building surface or group of surfaces to solar energy. Finally, students are asked to identify and analyze case studies where the building form is generated out of the need to manipulate the impact of solar energy.

\section{Nature and design manipulation of wind energy}

The objective here is to help students manipulate moving air to achieve human thermal comfort as well as to generate energy. The subject starts with explaining the nature of wind and how to interpret wind data. The difference between wind speed and direction (typically collected at airports) and the actual wind speed and direction at a particular site is emphasized. The software Climate Consultant (Ligget and Mine, 2011) is used to show hourly changes in wind direction, and also for discussion on the possible design implications of these changes. The contents then 
cover the flow of wind around buildings and how building forms can be used to manipulate wind pressure. The strategies of using cross and stack ventilation are discussed along with the factors that affect the flow and the speed of air in each of those two ventilated techniques. Finally, students are asked to identify and analyze case studies where the building form is generated out of the need to manipulate air movement within and around the building.

\section{Nature and design manipulation of the thermal energy of air}

The objective here is to help students understand how to manipulate both sensible and latent heat contents of the air to achieve human thermal comfort. The subject begins with an exploration of the relationship between air, its vapor, and their energy contents by explaining the psychrometric chart. The human thermal comfort zone in the chart is discussed along with the extended zone that considers the effects of air movement and thermal radiation. The chart is then used to explain the use of different design strategies to move air condition from one zone in the chart to the human comfort zone. For example, the need to increase sensible heat gain through solar energy in the case of the cold climate of Montreal, to reduce air temperature and increase humidity using the adiabatic process in hot and dry climate of Riyadh, or to increase wind movement in the hot and humid climate of Bangkok (Figure 2). Examples of architectural forms that are generated using different design strategies are shown and analyzed.

\section{SUMMARY AND CONCLUSION}

The course assessment methods support that the course successfully achieves its stated outcomes. However, integrating the knowledge gained in this course into the rest of the curriculum remains a challenge. A three credit-hour lecture course is pedagogically insufficient to make energy performance a design priority for students. Unfortunately, many students who did well in the course failed to capitalize on the knowledge gained when designing their studio projects. The author believes that this is due to the following reasons:

Many studio professors put very little or no emphasis on energy performance during the conceptual design stage. While it is expected that emphasis on design issues varies from one studio to another, the author believes that there is currently a moral obligation by the architecture education community to sustain energy performance as an issue of high priority throughout most or all studio experiences. Energy efficient designs should be the norm in studio submissions, as is the case with structurally sound designs.

Energy performance is viewed by a segment of architecture educators as an engineering aspect of design. This seems to be the result of the long-term under-emphasis of the issue in architectural education. This apparently resulted in a generation of educators who are lacking the fundamentals of designing with energy performance in mind. Some try to overcome the problem by using simple and fashionable terminologies that show that they care about the subject. Unfortunately, they use no systematic approach to determine what does and what 
does not make design sense. The author therefore suggests that technology professors make workshops for their colleagues who missed the opportunity to learn enough about the fundamentals of energy performance to upgrade their knowledge and skills in this aspect of design.

Finally, the author hopes that this paper will trigger a greater amount of documented discussion on ways to teach the fundamentals and applications of energy performance of buildings to architecture students.

\section{REFERENCES}

AIA (2006). Ecological Literacy in Architecture Education, The American Institute of Architects, The AIA Committee on the Environment, http://www.aia.org/ practicing/groups/kc/AIAS074665 (accessed May 15, 2012)

ASHRAE (2009). ASHRAE Handbook - Fundamentals, American Society of Heating, Refrigerating and Air-Conditioning Engineers.

Autodesk (2012). http://usa.autodesk.com/ecotect-analysis/

The Carbon Neutral Design Project (2009), http://www.architecture.uwaterloo.ca /faculty_projects/terri/carbon-aia/tools1.html

Hutcheon, N., Handegord, G. (1995). Building Science for a Cold Climate, National Research Council of Canada.

Earley, S. (2005). Ecological Design and Building Schools: Green Guide to Educational Opportunities in the United States and Canada, New Village Press, Oakland

Marsh, A.J. (1996). Heatwin, software developed as part of doctoral work at the School of Architecture and Fine Arts, The University of Western Australia

McMullan, R. (2007). Environmental Science in Building, Palgrave Macmillan.

Mokhtar, A. (2006). "Educational Architecture-Oriented Software Linking Conceptual Design and Solar Intensity,” Journal of Architectural Engineering, ASCE, 12 (2): 100-105.

Olgyay, V. (1992). Design with Climate: Bioclimatic Approach to Architectural Regionalism, Princeton University Press.

Pohl, J. (2011). Building Science - Concepts and Application, Willey-Blackwell, UK.

Ligget, R. and Mine, M. (2011), Climate Consultant 5, UCLA Energy Design Tool Group, http://www.energy-design-tools.aud.ucla.edu/ (accessed May 15, 2012)

SBSE and AIA (2012). The Carbon Neutral Design Project - Carbon Calculation Tools, Society of Building Science Educators and The American Institute of Architects, http://www.architecture.uwaterloo.ca/faculty_projects/terri/carbon -aia/tools1.html (accessed May 15, 2012)

Szokolay, S.V. (2008). Introduction to Architectural Science: The Basis of Sustainable Design, Architectural Press.

U.S. Department of Energy (2010). eQUEST- the QUick Energy Simulation Tool, http://doe2.com/equest/index.html (accessed June $3^{\text {rd }}, 2012$ )

U.S. Department of Energy (2011a). EnergyPlus Energy Simulation Software, http://apps1.eere.energy.gov/buildings/energyplus/ (accessed June $3^{\text {rd }}$, 2012) 
U.S. Department of Energy (2011b). OpenStudio Plug-in for Google SketchUp, http://apps1.eere.energy.gov/buildings/energyplus/openstudio.cfm/ (accessed June $3^{\text {rd }}, 2012$ ) 